\title{
Atividade docente: transformações do professor na perspectiva da psicologia sócio-histórica
}

\author{
Claudia Davis \\ Wanda Maria Junqueira Aguiar
}

\section{Resumo}

Este artigo, com base em pressupostos teóricos e metodológicos da Psicologia sócio-histórica e da ergonomia francesa atual, busca elucidar como subsidiar propostas de formação de professores que superem a dicotomia saber-ação para aprimorar a qualidade da escolarização oferecida. Explicita as principais categorias e conceitos empregados, bem como descreve os procedimentos utilizados por uma professora das séries iniciais do Ensino Fundamental em uma instituição pública da cidade de São Paulo. Finalmente, sintetiza os resultados e aponta, a partir destes, aspectos que poderão ser considerados nos processos de formação docente.

Palavras-Chaves: Formação de professores, atividade docente, Psicologia sócio-histórica.

\section{Teacher activity: teacher's transformation according to sociohistorical psychology}

\begin{abstract}
This article aims to demonstrate, through the theoretical and methodological assumptions of the social-historical approach in Psychology and those of the contemporary French ergonomic tradition, how it is possible to subsidize a teacher formation that does not promote a dichotomy between knowledge and action, improving, consequently, the quality of schooling. The main categories and concepts employed are explicated as well as the procedures used to collect data from a second grade teacher, working in a public institution located in Sao Paulo city, Brazil. Finally, a description and an interpretation of the collected data are presented, showing how initial and/or continuous teacher formation can be enriched by the type of analysis that was conducted.
\end{abstract}

Key-words: Teacher Formation, teaching working, Social-historic Psychology.

\section{Actividad docente: transformaciones del profesor bajo perspectiva de la psicología socio-histórica}

\section{Resumen}

Este artículo, con base en presupuestos teóricos y metodológicos de la Psicología socio-histórica y de la ergonomía francesa actual, busca dilucidar cómo subsidiar propuestas de formación de profesores que superen la dicotomía saber-acción, para mejorar la calidad de la escolarización ofrecida. Expone las principales categorías y conceptos empleados, así como también, describe los procedimientos utilizados por una profesora de los primeros grados de la educación básica primaria, en una institución pública de la ciudad de São Paulo. Finalmente, sintetiza los resultados e indica, a partir de estos, aspectos que podrán ser considerados en los procesos de formación docente.

Palabras-Clave: Formación de Profesores, trabajo docente, Psicología Socio- Histórica. 


\section{Introdução}

A profissão docente, no âmbito da formação e do trabalho, tem sido intensamente estudada (Oliveira, 2004; Santo, 2004; Talavera; 2004), em vista das grandes mudanças ocorridas no cenário mundial, trazendo novas demandas para a escolarização que, por sua vez, passa a fazer forte pressão para que o trabalho na escola seja mais efetivo. Com isso, há a necessidade de rever as atividades docentes, qualificando-as e ampliando seus efeitos. No entanto, a ausência de uma política bem definida acerca da formação docente tem criado grande desânimo no professorado e insatisfação com os resultados de seu trabalho. Tudo isso gera um grande desgaste nas relações internas da escola e tem repercussões na escolha pelo magistério por parte dos alunos que ingressam na universidade.

Gatti e Barretto (2009), em estudo recente sobre os impasses e desafios postos aos professores do Brasil, ressaltaram a dificuldade para formar bons quadros para a docência. Entre os problemas identificados, apontam a debilidade da formação profissional (seja ela inicial ou continuada) ministrada por muitas instituições, atuando de maneira desarticulada e sem os mesmos objetivos. A situação é agravada pela forte tradição disciplinar brasileira, que se opõe radicalmente às tentativas de se alcançar uma ação escolar integrada e interdisciplinar. Além disso, os currículos tendem a ser muito abstratos, deixando de incorporar preocupações de natureza pedagógica, diretamente vinculadas à prática profissional. Acima de tudo, falta entrosamento da teoria com a prática, aspecto que acaba fazendo da docência uma profissão sem conhecimentos aprofundados, sem método, voltada para um aluno idealizado. Tudo isso redunda, como seria de se esperar, na visão de que o magistério é uma profissão de menor categoria e de que aqueles que a exercem não podem, portanto, ser profissionais valorizados. Estágios sem planejamento e sem supervisão, pouca clareza acerca do que vem a ser um trabalho docente eficaz, fronteiras difusas ocultando as especificidades da Educação Infantil, do Ensino Fundamental e do Médio só fazem agravar a pouca ou nenhuma ênfase dada à função social da escolarização: transmitir às novas gerações os conhecimentos socialmente produzidos e, nesse movimento, consolidar valores e práticas centrais para o convívio humano respeitoso.

A urgência de se contar com professores mais bem preparados, capazes de lidar com a diversidade de perfis de alunos que frequentam o Ensino Básico, foi bem apontada por Libâneo (2003). Para o autor, é preciso contar com professores que, à luz da nova sociedade, dos conhecimentos ora requeridos e dos muitos e variados universos culturais dos alunos, consigam oferecer um ensino de melhor qualidade. Assim, a importância de formar melhor os futuros docentes, dotando-Ihes de "cultura geral mais ampliada, maior capacidade de aprender a aprender, competência para saber agir na sala de aula, habilidades comunicativas, domínio da linguagem informacional, saber usar meios de comunicação e articular as aulas com as mídias e multimídias" (2003, p. 10).
Essas habilidades, no entanto, exigem uma reconfiguração da identidade profissional. Mais preparados para o magistério, os docentes poderão lutar de modo mais efetivo por melhores salários, condições de trabalho e, principalmente, por aprimoramentos na formação, aspecto central no processo de qualificação docente (Nóvoa, 2004). Ainda, segundo Nóvoa, essa perspectiva é factível, desde que as agências formadoras de quadros para o magistério levem em conta a pessoa do educador, ou seja, sua história, seu aprendizado, sua experiência particular. Com isso, fica mais plausível para os professores manterem-se atualizados em termos de conteúdos e métodos de ensino, diversificando as práticas pedagógicas para ensinar a tantos e variados alunos. Como a docência requer contínuo aprimoramento, o autor indica que, uma vez formado, o professor deve continuar estudando e se atualizando. Para tanto, sugere o autor, é preciso fugir de iniciativas individuais e privilegiar, na formação continuada, iniciativas de natureza coletiva, que ocorram no próprio local de trabalho. Vale lembrar que as modalidades de formação em serviço têm sido alvo de constantes e severas críticas (Freitas, 2002; Gatti, 2003). Entre elas, destaca-se a formação que se volta para enfoques extremamente conteudistas e pragmáticos, que valorizam a apropriação de informações e o trabalho com racionalidade como as únicas formas de alterar posturas e formas de agir.

Sobre as dificuldades de formação de professores na França, Durand e cols. (2005) apontam que elas decorrem da cisão entre o que chamam "epistemologia dos saberes" (ligada ao saber e ao rigor científico) e a "epistemologia da ação" (voltada para a pertinência profissional), que se reflete na organização e administração dos institutos universitários de formação de professores. Tais dificuldades poderiam ser sanadas pela análise adequada do trabalho docente, com base na qual seria possível tentar desenvolvê-lo, articulando formação e pesquisa. Essa tentativa tem sido feita pela escola ergonômica francesa contemporânea (Clot, 1999) e suas variantes, que se preocupam em dar maior visibilidade às atividades dos professores e às formas pelas quais elas se desenvolvem.

\section{Pressupostos teórico-metodológicos}

Tomou-se, nesta pesquisa, um conjunto de pressupostos retirados tanto da Psicologia sócio-histórica como da ergonomia francesa, articulando-os de uma maneira diferente daquela que Clot (2006) propõe. Isso é possível na medida em que as duas vertentes têm as bases teóricas no materialismo histórico-dialético, que implica uma concepção de homem como ser social, histórico e constituído nas e constituinte das relações sociais. Nessa vertente epistemológica, algumas categorias são centrais e, por essa razão, serão brevemente apresentadas.

A primeira delas é a de mediação, como "uma instância que relaciona objetos, processos ou situações entre si; o conceito que designa um elemento que viabiliza a realização de outro e que, embora distinto dele, garante a sua 
efetivação, dando-lhe concretude" (Severino, 1992, p. 44). A mediação, como categoria teórico-metodológica, permite romper com dicotomias e identificar as determinações dialeticamente constitutivas do sujeito (Aguiar \& Ozella, 2006). Essa categoria possibilita explicar/compreender que, embora o homem possa, potencialmente, como membro da espécie humana, alcançar sua humanidade, ele só o faz por meio das relações sociais que mantém com outros homens e com a cultura até então acumulada.

A segunda categoria diz respeito à história, entendida tanto como movimento dialético da realidade (marcado pela relação parte-todo, pela unidade dos contrários, pela distinção aparência-essência) quanto como ordenamento significativo dos fatos, o que requer certo nível de consciência e de intencionalidade. Fica mais fácil perceber, assim, como o trabalho e a fabricação de instrumentos físicos e simbólicos possibilitaram ao homem criar as condições de sua própria existência, assumindo o controle de sua evolução e, portanto, de sua história.

A terceira categoria é a de atividade que, no caso dos homens, distancia-se em muito daquela dos animais. A atividade humana voluntária é constituída por meio de inúmeras mediações que só são possíveis no e pelo convívio social, no trabalho conjunto. Dessa maneira, a atividade humana e suas inovações são transmitidas culturalmente de geração em geração, permitindo que o natural se converta em social, conforme discute Leontiev (1978, p. 201) sobre o processo de humanização, que envolve atividade, pensamento e linguagem e os desdobramentos decorrentes das mediações mantidas entre esses.

A significação, quarta categoria, é formada por duas outras: a dos sentidos e a dos significados atribuídos à realidade (referente) e aos signos (referência), dentre os quais a palavra ganha destaque. Categorias distintas, sentido e significado não podem ser compreendidos isoladamente. O significado, no campo semântico, refere-se sempre aos eventos, objetos, fenômenos do mundo empírico - aos referentes - e os representam. Já no campo psicológico, é uma generalização, um conceito, produções históricas e sociais por meio das quais os seres humanos se comunicam e socializam experiências. Para melhor compreender o sujeito, os significados constituem o ponto de partida, pois, contendo mais do que aparentam, pode-se, por meio deles, caminhar para as zonas mais instáveis, fluidas e profundas: as de sentido. Essas, por sua vez, são sempre muito mais amplas que as do significado, por constituírem uma articulação particular de eventos psicológicos, realizada pelo sujeito em sua relação como o mundo. O sentido permite uma apreensão mais precisa do sujeito como a unidade dos processos cognitivos, afetivos e biológicos. Ação, pensamento e afeto jamais se separam e é essa unidade que explica os motivos e as causas do pensamento, dos afetos e das atividades. Entender o sujeito implica, portanto, aproximar-se das zonas de sentido.

A ergonomia francesa contemporânea assume parte importante dos pressupostos teóricos e metodológicos da Psicologia sócio-histórica. Agrega, no entanto, a essa pro- posta, outras categorias analíticas, como a de "real da atividade", "atividade real", "gênero" e "estilo". O real da atividade, nessa visão, não é apenas aquilo que foi feito, porque isso é justamente a atividade real. O real da atividade, conforme Clot (2006, p. 16), envolve também aquilo que não o foi, ou seja: aquilo que não se fez, que não se pôde fazer, que se tentou fazer sem conseguir, que se teria querido ou podido fazer, que se pensou ou que se sonhou poder fazer, o que se fez para não fazer aquilo que seria preciso fazer ou o que foi feito sem o querer. Esse autor chama a atenção para o fato de que ações envolvem pensamentos e afetos e, ao se pretender apreender o "real da atividade", é preciso mobilizar o sujeito para que ele revele o que pretendeu fazer e não foi feito, tudo aquilo que, vislumbrado ou planejado, ficou, de alguma forma, reprimido. As ações e afetos que não se efetivaram não deixam, no entanto, de exercer influência na atividade do sujeito, uma vez que não podem ser totalmente controladas (Clot, 2006).

A categoria "gênero" faz a mediação dos sujeitos entre si e deles com seus objetos de trabalho, constituindo tanto a "atividade real" quanto o "real da atividade". Em especial, pode-se dizer que, quanto maior a compreensão do gênero, maior será a compreensão das atividades daqueles que as executam: os sujeitos. Gênero refere-se às regras escritas e subentendidas que permitem ao sujeito situar-se diante da novidade e, ao mesmo tempo, limitam, muitas vezes, sua ação. O gênero envolve o conjunto de procedimentos, atitudes e posturas construídas, no processo sócio-histórico em dado campo profissional: são mediações que concorrem para a realização da atividade, constituindo, de fato, prescrições que refletem a tradição e a história profissional do grupo ao qual o sujeito pertence. A atividade é, portanto, sempre mediada pelo gênero, que, por ser de natureza essencialmente social, encontra-se em constante movimento. Assim, regras, atitudes e posturas são construídas incessantemente na e pela atividade, cabendo ao gênero definir as frágeis fronteiras entre o aceitável e o inaceitável no trabalho. É também o gênero que obriga o sujeito a enfrentar barreiras e a superálas de forma inovadora.

Quando isso ocorre, surge o "estilo pessoal": a possibilidade individual de transformar o que foi prescrito pelo gênero social mediante os recursos disponíveis para a realização da atividade (Clot, 2006, p.49). O estilo pessoal relaciona-se mais estreitamente ao sentido da atividade para o próprio sujeito, diz respeito à subjetividade e se refere, também, à maneira pela qual ele se apropria do gênero, das regras socialmente construídas pelo grupo profissional, transformando-o segundo suas próprias peculiaridades. Trata-se de um "jeito" de fazer singular e, ao mesmo tempo, social e histórico. De certa forma, o estilo pessoal tem um peso grande na contínua e constante renovação do gênero: se o estilo se mostrar efetivo, acaba sendo incorporado ao gênero, ampliando as possibilidades de ação do sujeito, ou seja, ampliando suas possibilidades de transformação pessoal e profissional. A análise da atividade realizada por intermédio da autoconfrontação simples e cruzada permite verificar o quanto a mediação do gênero e do estilo pessoal 
são constitutivas da atividade do sujeito, permitindo que se alcance tanto uma apreensão mais completa e profunda dela (para além de sua aparência) como dos sentidos que os sujeitos lhe deram.

Se o real da atividade ultrapassa a própria atividade realizada, englobando tudo aquilo que se revela possível, improvável ou inesperado no contato com a realidade, ele não pode ser diretamente observado. Nesse caso, como estudar e compreender a atividade? Clot (2006) propõe um novo método de investigação. Nele, episódios da atividade do sujeito são previamente selecionados pelos pesquisadores. Em seguida, é importante que o sujeito da atividade os analise, contrastando o que foi concebido com o que foi realizado. Isso é feito em três momentos. O primeiro deles consiste na auto-observação, situação em que o sujeito se observa na ação e entabula um diálogo interno com o real da atividade. No segundo momento, denominado autoconfrontação simples, o sujeito descreve os episódios que acabou de ver para o pesquisador. Com isso, o sujeito passa da situação de "observado" à de "observador": sua análise decorre das interpretações feitas no momento anterior, o de autoobservação. Ao descrevê-las, a atividade, que antes era essencialmente intrapsicológica, torna-se interpsicológica. O vivido transforma-se ao ser revivido: deixa de ser "objeto da atividade" para se tornar em meio de nela pensar.

Dessa maneira, as experiências do sujeito, ao se exteriorizarem, revelam-se ainda vivas, embora sob outra configuração: não é mais apenas o que foi possível fazer ou alcançar, mas também aquilo que não foi nem feito nem alcançado e, ainda, aquilo que poderia ou deveria ter sido feito. De fato, ao observar e comentar sua atividade, diferenças ora sutis, ora marcantes, entre o que se pretendia fazer, o que foi efetivamente feito e o que poderia ter sido feito aparecem. Abre-se, consequentemente, a possibilidade de organizar o vivido, de apreendê-lo por outras óticas que revelam possibilidades e limites até então desconhecidos. Com isso, o pesquisador é levado pelo sujeito a compreender a significação que ele atribuiu à própria atividade observada, avançando, portanto, em direção às zonas de sentido.

O terceiro momento - a autoconfrontação cruzada - ocorre quando os mesmos episódios são vistos novamente, agora pelo sujeito, por um especialista ou colega de trabalho (alguém que desempenhe a mesma atividade) e pelo pesquisador. Nesse momento, o sujeito não se dirige mais apenas e exclusivamente à atividade realizada: ele se volta também para as observações feitas, pelo seu colega, sobre as atividades que aparecem no vídeo. Há uma retomada da análise, que agora é feita pelo colega de trabalho. Seus comentários dirigem-se a diferentes interlocutores (o sujeito - aquele que realizou a atividade - e o pesquisador) e variam, dependendo de a quem se destinam. A fala permite aos outros pensarem, sentirem e agirem de acordo com a perspectiva daquele que a emprega.

\section{Método}

\section{Objetivos}

Esse estudo investiga a atividade docente, fazendo perguntas interligadas, de modo que a resposta alcançada em uma delas possa constituir subsídios para a compreensão da outra. São elas:

- Quais são os sentidos e significados que o professor atribui à atividade docente?

- Como se dá a dinâmica do desenvolvimento profissional do sujeito pela observação e análise de sua própria atividade docente?

\section{O contato com a escola}

A escola e a professora foram contatadas diretamente pelas pesquisadoras, uma vez que os professores em geral negam-se a participar de estudos em que suas aulas são filmadas. Decidiu-se escolher, portanto, dentre o círculo mais próximo das pesquisadoras, uma diretora bem preparada, que imprimia, com firmeza, uma gestão coletivamente acordada em sua escola. As pesquisadoras apresentaram a pesquisa: seus objetivos, o método a ser utilizado e os benefícios esperados à diretora, que imediatamente se lembrou de Nina, uma profissional muito bem-conceituada na escola.

\section{A professora}

Nina era uma moça de 30 anos de idade, casada, sem filhos, formada em Pedagogia em uma universidade da rede privada da grande São Paulo. Aceitou participar da pesquisa a pedido da diretora. Há quase 12 anos atuava no magistério, inicialmente em escolas da rede particular e, mais tarde, concursou-se para o ensino na rede pública. Como professora polivalente, sua preferência estava em ensinar a ler e escrever. Língua Portuguesa era, assim, a disciplina que recebia maior atenção.

\section{Instrumentos de coleta de dados}

Os instrumentos de coleta de dados foram os seguintes:

a) História de vida da professora: a professora, em narrativa, salientou, conforme instrução prévia, como via sua atuação profissional, o papel da escola e da educação, sua compreensão acerca do processo de alfabetização e seu preparo profissional para levá-lo adiante, indicando as eventuais dificuldades que encontrava.

b) Observação do espaço físico da escola: as pesquisadoras observaram o espaço físico da escola e obtiveram, 
com a secretaria, dados que permitissem compreender meIhor seus atores e dinâmica de funcionamento.

c) Filmagem: para fins de observação e discussão, foram filmadas atividades realizadas por Nina com seus alunos.

d) Seleção de episódios (trechos da atividade "aula", com começo, meio e fim): para serem vistos, analisados e comentados pela professora, primeiramente com a pesquisadora que tinha feito tanto a entrevista como as filmagens das aulas e, posteriormente, com outra pesquisadora. Os critérios adotados para selecionar os episódios foram: evidenciar diferença e/ou contradição entre a atividade prescrita e a atividade real ou o relato de Nina, quando, da história de vida, incidir em uma situação que poderia ser conduzida de diferentes formas, permitindo explorar o que se pretendeu fazer, o que foi feito e o que poderia ter sido feito de outra maneira. A duração de cada episódio variou de alguns poucos minutos até quase um quarto de hora. Foram extraídos episódios de três aulas, sendo que apenas o primeiro será aqui analisado. Nele, a professora tratou de conteúdos de Língua Portuguesa, por meio de diversas atividades individuais e grupais, além de interação mais intensa com um grupo de 4 alunos, para desenvolver a linguagem oral e o vocabulário.

e) Realização das autoconfrontações simples e cruzada: episódios selecionados foram apresentados em vídeo, para que Nina pudesse, em um primeiro momento, observarse. Depois, ela descreveu suas impressões com a pesquisadora que a filmara e, finalmente, com a outra pesquisadora, que seguia de perto a proposta da Secretaria de Educação do Estado de São Paulo -SEE-SP - e estava familiarizada com o processo de alfabetização.

\section{Referencial de análise}

Foram adotados dois procedimentos distintos para analisar os dados coletados:

a) o proposto por Aguiar e Ozella (2006) para organizar e analisar os dados coletados na história de vida. As fitas contendo a narrativa de Nina foram transcritas e lidas meticulosamente. Em seguida, os conteúdos tratados pela professora foram agrupados por similaridade, complementaridade, contraposição, contradições neles encontradas ou por qualquer outro aspecto que levasse a menor diversidade de temas. Com isso, pré-indicadores foram formados. A seguir, agruparam-se os pré-indicadores, com o mesmo critério anteriormente empregado. Indicadores resultaram da fusão dos pré-indicadores, indo-se buscar, no material coletado, trechos que melhor ilustrassem seus conteúdos. O passo seguinte foi inter-relacionar os indicadores encontrados até obter uma nova articulação deles: os núcleos de significação. Especial interesse foi dado às contradições encontradas nas falas da professora, uma vez que, por seu intermédio, considera-se possível apreender os movimentos do sujeito. Atenção também foi dada à articulação de tais núcleos ao contexto social, cultural e escolar, bem como às categorias teóricas de análise.

b) o sugerido pela ergonomia francesa atual, em que os episódios selecionados são assistidos duas vezes: a primeira pelo pesquisador e pelo sujeito; a segunda com mais um assistente: um colega do sujeito que exerce a mesma função. Sucedem observação e diálogos sobre a atividade vista, sendo também registrados para fins de análise.

Finalmente, as informações colhidas por meio dos diferentes procedimentos foram reunidas para permitir alcançar os objetivos da pesquisa.

\section{Análise e interpretação dos resultados}

A escola selecionada é vinculada à rede pública da cidade de São Paulo. Possui um projeto pedagógico, elaborado com a participação da ampla maioria dos docentes e submetido ao Conselho de Escola. A sala de aula de Nina era composta por 21 alunos, com idades entre 8 e 12. Para participar da pesquisa, coletou-se a anuência, por escrito, da direção, da professora e dos responsáveis pelos alunos.

\section{Os sentidos da atividade docente}

Os núcleos de significação foram constituídos segundo a fala da professora, levando em consideração o espaço social e as relações histórico-sociais que constituem a subjetividade de Nina. $\mathrm{Na}$ análise da história de vida da professora, foram encontrados 32 pré-indicadores que, agrupados, resultaram em 5 indicadores. Esses últimos, por sua vez, ao serem novamente agrupados, forneceram dois núcleos de significação, apresentados a seguir:

\section{Núcleo 1: A formação teórica, técnica e prática}

Este núcleo indicou que a escolha profissional de Nina decorreu de uma crença, bastante idealizada, acerca do papel do professor, cuja importância era salientada em sua família. Assim, os elementos constitutivos da docência estavam vinculados à nobreza dessa profissão, gerando uma implicação pessoal: "eu escolhi ser professora muito cedo, porque minha mãe sempre dizia que a chave para mudar o mundo, transformar vidas e criar novos rumos para as pessoas estava nas mãos dos professores".

A opção pela docência não foi leviana: Nina relata ter até hoje prazer em ensinar. Segundo ela, fez uma boa faculdade de Pedagogia, realizou estágios em escolas interessantes e, sobretudo, aproveitou as oportunidades que a vida Ihe deu. Além disso, buscou aprimoramento profissional, concluindo, antes de se casar, uma especialização em Psicopedagogia. Esse percurso revela que, mesmo partindo de uma escolha sem muitos fundamentos e informações, a 
atividade docente adquiriu novos motivos geradores de sentidos, mantendo-a interessada no ensinar e concentrada em sua profissão.

Nina considera, no entanto, que, mesmo tendo se dedicado de maneira constante à construção de um cabedal teórico sólido, a principal fonte de conhecimentos sobre a atividade docente foi a prática. Como ela mesma diz, "é trabalhando que você se torna uma boa professora", muito embora ressalte que só a prática não conseguiria levá-la a isso. Em seu entender, a teoria foi ganhando sentido por meio da prática, no processo de ensinar os alunos. Suas palavras revelam a importância que dá ao conhecimento alcançado no dia a dia da escola: "Quando você vai ver, tudo está interligado: as condições que a escola oferece, a liderança da diretora, o domínio metodológico da coordenadora, os conhecimentos dos alunos quando chegam até nós, a nossa própria formação e a vontade de dar certo". Dá-se conta da importância do contexto sócio-histórico, mas não consegue retirar de sua fala a dicotomia entre prática e teoria, ou dito de outro modo, entre o saber e a ação. Pode-se supor que essa visão - que articula prática e teoria de modo mecânico, linear, não dialético - foi constituída ao longo da formação docente de Nina, tornando-se elemento fundante dos sentidos que Nina atribui à atividade docente. Talvez por isso seja tão difícil descartá-la. Salienta como foi árduo o começo de suas atividades profissionais: não estava, tal como vê hoje, preparada para enfrentar as demandas da educação. Achava que conhecia pouco, quase nada, e sentia muito medo de enfrentar uma sala de aula. Tratou de não deixar que esse temor fosse paralisante: foi fazer cursos oferecidos em escolas privadas sobre o processo de alfabetização, participou de capacitações proporcionadas aos professores das escolas nas quais trabalhou, investiu em si mesma. Lamenta não ter saído da faculdade com uma ideia mais precisa sobre o que era ser professora e, dessa forma, critica sua formação inicial:

Olha, eu fiz questão de fazer uma boa faculdade, porque eu sei que a educação é importante. Mas tem professores que a gente pega, que não dá: as aulas não são programadas; não se indica para que aquilo que se está aprendendo serve; os conteúdos vão sendo dados de maneira fragmentada, como se fosse obrigação nossa integrar informações fragmentadas.

Nesse discurso, vai aparecendo uma aluna contestadora, que não aceitava explicações pouco convincentes e que buscava "espremer todo o conhecimento dos professores", fato que lhe deu prestígio entre os colegas. Mais tarde, colheu os frutos de sua luta: formou uma rede ampla de relacionamentos e, por meio dela, recebeu sempre propostas de trabalho. Soube escolher bem. Trabalhou em escolas interessantes, onde foi aprendendo como ensinar mais e melhor. Inicialmente, disse que seguia à risca tudo o que Ihe sugeriam, tamanho era o pavor de fracassar. Mais tarde, veio a segurança para separar o joio do trigo. Aos poucos, na prática, foi construindo uma identidade profissional. Nina não se tornou professora de uma hora para a outra. Ao contrário, foi na e pela interação mantida nas escolas que foi se apropriando de modos de ser, pensar e agir que a levaram a se definir como tal.

É com convicção que Nina diz que se vê como alguém competente, capaz de dominar bem a sala de aula. Até dos maus professores conseguiu tirar lições importantes: não entrar na sala de aula sem ter feito um plano prévio, no qual busca explicitar o que vai ser ensinado, por que e para quê. No entanto, a confiança em si, se excessiva, pode ser prejudicial. Nina conta que, mais recentemente, com seu ingresso no magistério público, seu salário diminuiu e, com ele, também suas possibilidades de aprimoramento:

\footnotetext{
...eu sei que a gente precisa sempre fazer novos cursos, modificar o que sabe e o que faz, porque na vida nada é cem por cento certo. Tudo muda, porque a docência não há de mudar? O problema é que eu já investi muito em mim e agora, com o salário pela hora da morte, mal dá prá se segurar. Em São Paulo, tudo é longe, por conta do trânsito. De vez em quando, até que eu leio alguns livros, a Nova Escola, mas sem obrigação, a coisa acaba sendo sempre meia-boca.
}

A contradição parece estar bem aí: saber da importância de se capacitar continuamente e, ao mesmo tempo, furtar-se a isso. Esse é o caso da pós-graduação, uma meta muito almejada, mas sempre postergada por temer não passar na seleção. Acreditava que um insucesso, nesse nível de ensino, teria um efeito catastrófico na escola e entre conhecidos, arruinando uma reputação construída com esforço e dedicação: "Eu bem que queria fazer uma pós, mas quem disse que me aceitam? Eu fico só imaginando o vexame e o diz que diz: Nina não passou, levou bomba, era só fachada..." Elemento constitutivo desta contradição é o embate entre as esferas afetivas e cognitivas, entre angústias de fracasso e a necessidade de seguir se aprimorando. Talvez essa divisão estivesse represando o movimento de Nina em busca de uma formação mais sólida.

Chama a atenção o fato de a professora demonstrar, de um lado, segurança e confiança em si mesma e, de outro, insegurança, medo de não ser bem-sucedida e de perder sua boa reputação. Os sentidos construídos por Nina sobre sua formação e sua prática mostram-se complexos e contraditórios. Para Rey (2004), "o sentido nunca é apreendido automaticamente” (p. 57): ele é inesgotável, fluido, único, mas sempre comprometido com a dimensão histórica. Nina, como muitas outras professoras, ao mesmo tempo em que almeja aprimorar sua prática, duvida desta possibilidade: quer ser melhor professora, mas a amedrontam os obstáculos impostos pela realidade social, escolar e subjetiva. Sente-se insegura.

Contradições como essa, tônica desse núcleo, geram situações de crise, de instabilidade, fornecendo indícios de que a professora está atenta ao seu movimento, no entanto, ainda sem vislumbrar possibilidades de superação. Clot (2001) salienta que o desenvolvimento subjetivo é necessário para que "a experiência vivida possa se transformar 
em meio de viver outras experiências" (p. 10), sendo que, na situação discutida, não nos parece que tal movimento tenha ocorrido.

\section{Núcleo2: A vivência profissional e as possibilidades abertas pela escola}

Ao relatar sua história de vida, Nina também menciona sua atividade docente, chegando, inclusive, a reconhecer que precisa de maior aperfeiçoamento para lidar com as questões de alfabetização. Nesse momento, surgiram muitas reflexões importantes sobre a atividade realizada, evidenciando seu processo de configuração. Como "o sentido real de cada palavra é determinado, no fim das contas, por toda a riqueza dos momentos existentes na consciência e relacionados àquilo que está expresso por uma determinada palavra" (Vygotski, 2000, p. 466), foi ficando mais claro como se delineava, para Nina, sua vivência profissional. Disse ter ficado muitos anos trabalhando apenas com crianças de $5^{a}$ à $7^{a}$ série, por sentir que havia, aí, conteúdos a serem tratados: afligia-se com a possibilidade de se perder nas classes iniciais, de confundir seu papel de professora com o de mãe, de não ter a paciência necessária para lidar com crianças de pequena idade.

Há dois anos, incentivada pela diretora, aventurouse a assumir a regência de classes iniciais. Desde então, atuava na $2^{\mathrm{a}}$ série, preferida em razão de as crianças já terem tido pelo menos um ano de escolarização e estarem familiarizadas com o contexto escolar. Disse ter sofrido muito com o período de adaptação de crianças na $1^{a}$ série, que ficava com o "coração apertado quando a mãe ia embora, a criança desacorçoada, perdida, sem nenhuma referência na escola". Tornar-se essa referência, ser continente às necessidades de segurança dos alunos foi uma experiência importante, mas que Nina não quer repetir. Além disso, tinha interesse pelo processo de alfabetização, tendo visto o precário domínio da língua que os alunos apresentavam ao final da $1^{\text {a }}$ série. Considera que, nessa escola, mediante incentivo da diretora, dos colegas, dos próprios alunos e de suas respectivas famílias, enfrentou desafios que jamais se julgou capaz. Além do apoio aí encontrado, credita esse processo de assumir riscos a dois outros fatores:

1. ser professora efetiva da rede, porque isso fez com que perdesse o medo de ser despedida;

2. a renomada competência da equipe gestora, cuja opinião sempre pesou muito em suas escolhas.

Se todos acreditavam nela, por que não tentar, em especial quando apoio e orientação estavam disponíveis? Forjou-se, nessa escola, uma professora alfabetizadora que se sabe bem-sucedida e, contraditoriamente, disso duvida.

Ser professora das séries iniciais é, para Nina, ocasião única de oferecer às crianças os fundamentos necessários para que aprendam e se desenvolvam conforme o pre- visto. No entanto, a professora não é imune aos estereótipos veiculados na área da Educação e, por isso, acredita que o fracasso escolar decorre diretamente da falta de interesse dos pais pela escolarização dos filhos. Em seu entender, se esse problema pudesse ser contornado, a escola, os professores e os próprios alunos teriam maior probabilidade de sucesso.

Essa concepção, compartilhada por muitos outros professores, revela significados sociais extremamente presentes no cotidiano escolar. Daí ser interessante observar a professora: ao mesmo tempo em que supera obstáculos e se aventura em novas iniciativas, toma para si concepções que camuflam o real, ao isentar a escola e seus respectivos professores de responsabilidades. Essa é, possivelmente, uma maneira de enfrentar as contradições, de se tranquilizar, de não alimentar percepções que possam ser sofridas. Clot (2006) afirma que a atividade é sempre uma difícil escolha subjetiva e ter a quem atribuir seu fracasso parece apaziguar o desapontamento. Nina tem especial apreço pela oportunidade de realmente atuar em parceria e em pertencer a uma equipe de professores que se apóiam na direção da escola e que, por sua vez, também a apóia. Outra coisa de que gosta na escola é que se percebe como parte de um trabaIho interdisciplinar. Para Nina, a vivência em equipe tem um sentido muito positivo: produz sentimentos de pertencimento ao grupo, de participação nas decisões. Segundo ela, para a escola realizar um trabalho competente, é preciso que ele seja coletivo. Esse sentido, por sua vez, é indutor de outras ações e significações, que levam a uma qualificação positiva da atividade docente.

\section{O episódio selecionado e seu contexto}

Depois de dar boas-vindas aos alunos e fazer a chamada, a professora iniciou a aula pedindo aos alunos que mudassem de lugar. Avisou que iria trabalhar mais de perto com 3 meninos e 1 menina e que, no meio tempo, os demais deveriam formar pares ou trios, preferencialmente. Se algum aluno quisesse trabalhar sozinho, ela também aceitaria essa decisão. As crianças deveriam ler as lições de casa e identificar eventuais erros, que seriam, posteriormente, corrigidos na lousa. Dois alunos optaram por ficar sozinhos. Formados os agrupamentos, a professora fez interferências na composição dos pares ou trios, justificando que, dessa maneira, o trabalho ficaria mais interessante. Em seguida, voltou-se para os 4 alunos que precisavam desenvolver melhor sua expressão oral.

Em um episódio, gravado em vídeo, Nina propõe aos alunos que a orientem como embrulhar um livro para presente, tentando fazer com que os alunos utilizem vocabulário que descrevam ações precisas. Ela acaba encerrando a atividade antes do previsto, porque uma aluna declara que está achando esta atividade chata.

Ao assistir ao vídeo, a professora, inicialmente, observou o episódio atenta e silenciosamente. Em seguida, a pesquisadora pediu que ela descrevesse, explicando mais 
detalhadamente, o que tinha feito e por quais motivos, se achava que as coisas tinham se passado conforme esperava, os problemas que surgiram etc. Nina começou dizendo que estava procurando mostrar que é preciso falar de forma clara, concisa e objetiva para poder se comunicar e ser entendido. Disse que reconhecia que essa não era uma tarefa fácil, mesmo para adultos. Foi pontuando que, quando auxiliou as crianças, ofereceu-lhes formas mais lógicas de se expressar, mais objetivas, palavras mais precisas e variadas. Falou que fez uso de alguns recursos usualmente empregados pelos professores nessas situações - dar modelo, fazer perguntas e discutir as respostas. Deu-se conta de que algumas crianças se cansaram, uma especialmente. Ao que tudo indica, com a fala de uma aluna, Nina percebeu que a atividade estava ficando penosa demais para todos e, por isso, decidiu encerrá-la antes de seu término. A seguir, uma síntese da fala da professora no decorrer da autoconfrontação simples:

Eu procurei, com essa atividade, expandir o vocabulário dessas crianças, que eu acho que são as que têm mais dificuldade de se expressar [...] estava até indo bem, com todos envolvidos e participando bastante, até a A2 dizer que o que a gente estava fazendo era chato e desnecessário. Daí, eu acho que me perdi: não estava esperando por isso [...] As coisas precisam fazer sentido para as crianças na escola e na vida. Daí, eu tentei me explicar, mas não deu muito certo. Acho que o A3 foi o que mais cooperou comigo e quem mais se envolveu na tarefa. [...] Eu estimei mal o tempo: demorou mesmo muito para eles darem ordens diretas e precisas e, também, eu acho que eu não tinha me dado conta antes de como é difícil falar tudo direitinho para o outro entender. [...] De um modo geral, eu acredito que eu posso melhorar, mas até eu acho que eu fiz o que precisava fazer: dei ajuda quando eles precisavam, mostrei a importância de falar com clareza, fiz perguntas adequadas para eles e respondi às que eles me fizeram da melhor forma possível. Eu gostei dessa parte. [...] É que na prática, as coisas são mesmo muito mais difíceis. A gente quer uma coisa total, boa para todos eles, mas não consegue antecipar, por melhor que a gente conheça as crianças, o que eles vão fazer. [...] Acho que eu preciso avaliar melhor a duração das atividades que eu programo. [...] Só isso. E já é muito, né? Eu não gostei de me ver dando aula.

No relato, Nina destaca claramente o objetivo da atividade, o que permite acompanhar seu movimento, ou seja, as transformações ocorridas em sua fala sobre a atividade prescrita, representada, aqui, pela meta da atividade. Foi possível, então, observar e analisar tanto os movimentos da própria subjetividade da professora, como aqueles de sua atividade. Esse movimento não é aqui entendido como avanço ou progresso e, sim, como alterações, plenas de conflitos, contradições, medos, nas formas de pensar e sentir da professora. Um primeiro movimento, fortemente tensionado pela emoção, é quando Nina afirma "eu meio que desmoronei! Até minha cara mudou!". Confrontar-se consigo mesma, ver-se por meio do olhar do outro, mobiliza novas formas de pensar e sentir a realidade vivida. Novos sentimentos surgem e pressionam a mudança no sentido atribuído à atividade: "então, por conta disso, pareceu mesmo que era uma coisa tonta e inútil e eu não acho legal quando isso ocorre". Presencia-se aí um momento de desequilíbrio, de desestabilização de sentidos, de mobilização de novas formas de significar a realidade? O que se pode dizer é que Nina já duvida da atividade proposta, de sua eficácia para atender a seus objetivos. Daí a explicação para rever o planejamento feito, em especial o tempo gasto na atividade e, inclusive, as metas, questionando se seu grau de dificuldade era compatível com o desenvolvimento cognitivo e afetivo dos alunos. É interessante observar, neste momento, o potencial da estratégia de autoconfrontação: observar a atividade é vivenciá-la novamente, decifrá-la de algum modo e, também, como lembra Clot (2006, p. 135), "encontrar, sem forçosamente procurar, alguma coisa de novo em si mesmo". Novas contradições engendram-se. Apesar de todas as dúvidas e incertezas, da tensão vivida, Nina ainda reafirma a sua prática.

Como já destacado, os sentidos constituídos por Nina acerca de sua atividade revelam, ao mesmo tempo, segurança e certezas, medo de não ser bem-sucedida, desejo de o ser. Em especial, apavora-a a ideia de que este fracasso se torne público ao ser presenciado pelas pesquisadoras: "Eu não gostei de me ver dando aula". Quem gosta? Paulo Freire (1992), ao discutir o trabalho do professor, perguntase se eles não temem o constrangimento de reaprender sua profissão diante dos colegas de trabalho e dos próprios estudantes. Pondera que a necessidade de se recriar na atividade profissional deve intimidá-los. Nina talvez viva essa situação. Mas isso a leva à paralisia ou vai impulsioná-la a buscar novas alternativas e novas práticas?

Tudo indica que Nina tenta escapar desse desconforto e encontrar um lugar mais confortável para si mesma. Inicia, então, a busca de explicações para as dificuldades encontradas. Afirma, por exemplo, que "na prática, as coisas são mesmo muito mais difíceis", resgatando a antiga e ainda não superada discussão acerca do papel da teoria na prática, tendendo a achar que "na prática, a teoria é outra". Os sentidos de Nina sobre a atividade docente encontram-se atravessados cognitiva e afetivamente por esta concepção, de modo que reluta em desconstruir essa apreensão do real. Ainda não consegue romper com proposições tão criticadas no campo educacional. Seguramente, a explicação dada por Clot (2006) é bastante convincente: a atividade é muito mais do que parece.

Concepções dicotômicas como essa, referentes à relação mantida entre a teoria e a prática, só podem ser ultrapassadas se forem processadas tanto na dimensão objetiva como na subjetiva, de maneira integrada e dialética. E Nina avança, ao concluir ser preciso "avaliar melhor a duração das atividades". Neste momento, mesmo sem a clareza da totalidade das questões envolvidas, ela percebe que não se trata simplesmente de alterar sua prática; é preciso modificar, necessariamente, aquilo que concebe como atividade, 
uma questão que implica conhecimento e prática, teoria articulada à prática ou, melhor dizendo, práxis.

$\mathrm{Na}$ sessão de autoconfrontação cruzada, quando a segunda pesquisadora comentou a mesma atividade analisada na autoconfrontação simples, a situação muda sensivelmente. A seguir, encontra-se a síntese dos aspectos centrais da transcrição desse novo encontro:

Pesq.: Eu gostei muito de poder ver o seu trabalho e queria agradecer muito essa oportunidade. Você não abandonou a classe e conseguiu fazer um trabalho diversificado, mas fez isso de uma forma que eu achei difícil. Gostei da ideia de trabalhar a expressão oral, mas ela não é fácil.

Nina: E eu que queria me sair bem... Também porque fui indicada pela diretora: não queria que ela ficasse desapontada comigo. Os estudos sobre o processo de alfabetização mostram que as crianças falam sem pensar no que dizem e isso dificulta a comunicação. É preciso ajudar as crianças a pensarem e falarem com clareza, e eu tento fazer isso. Quer dizer, tentei, porque não me saí tão bem como esperava. Não soube explicar isso para os alunos...

Pesq.: Posso fazer outra pergunta? Por que você não escolheu trabalhar com algum conteúdo curricular? Eu tentaria, por exemplo, plantar uma muda de flor em um vaso. Claro, você teria que ter uma sacola bem maior, cheia de saquinhos de areia, pedregulho e terra, além da planta em si. Mas as crianças trabalhariam da mesma forma: teriam que dar ordens precisas e diretas para preparar o vaso: o que vem antes, o que vem depois, razões disso e daquilo, enfim, você poderia cumprir seu objetivo e ensinar também questões relacionadas ao solo e ao plantio.

Nina: Nem me ocorreu fazer isso! Mas essa ideia é legal, porque eu poderia trabalhar outros conceitos, discutir conteúdo e forma. Foi bobagem mesmo... Já tinha me dado conta de que essa era uma tarefa ingrata, quando assisti ao vídeo pela primeira vez.

Pesq.: Trabalhar com conteúdos é uma forma de fazer ainda melhor o que você fez! Você criou condições para as crianças falarem, praticarem o emprego da linguagem oral, receber feedback da conversa por meio da própria conversa. Você variou as frases e ofereceu palavras alternativas, fez perguntas pertinentes, fez as crianças pensarem... A minha sugestão é que...

Nina: Que eu faça isso com conceitos, articulando a linguagem de todo o dia com os conhecimentos escolares.

Pesq.: Isso, eu não conseguiria me expressar melhor!

Nina: Acho que preciso estudar mais. Voltar a ler a Emília Ferreiro e a Ana Smolka... Eu gosto das propostas que elas fazem, porque essa é uma tarefa em que os alunos interagem bastante.

Pesq.: Claro. E nessa interação surgem oportunidades para usar uma variedade de palavras e, portanto, de conceitos, de maneira adequada. A gente não presta muita atenção, mas isso ajuda muito a tornar o pensamento mais claro, mais refinado.
Nina: Tem tanta coisa a fazer aqui na escola! Mas faz muita falta contar com material adequado! Imagine que ótimo se a gente tivesse uma horta ou um canteiro de flores. Porque não é só ter material: é saber fazer com que ele contribua para ampliar a experiência e o conhecimento dos alunos. Professor precisa disso: saber explorar melhor os materiais disponíveis. Mas isso ninguém ensina!

Pesq.: É verdade, capacitação nunca é suficiente. Mas, voltando para a sua sala, o vídeo mostra você trabaIhando muito com o A3 e ele me pareceu um menino que usa bem a linguagem. Por que você o incluiu no grupo?

Nina: Você achou isso, que ele domina bem a linguagem? Eu fico surpresa, porque ele tem 11 anos, vive com a avó e não é de fazer muitos amigos. É uma criança muito calada, introspectiva. Hoje, até que ele falou mais, mas eu achei que ele fez isso porque quis me ajudar.

Pesq.: Pode ser que eu esteja errada, mas veja as ordens que ele the dá. São bem precisas [voltam o vídeo]. Você não acha?

Nina: Aqui, nesse trecho, eu só estou percebendo agora, ele se mostrou bem competente. Eu estava tão atrapalhada nessa hora, que nem elogiei o suficiente. Acho que o fato dele participar e topar continuar participando foi o que não me deixou ficar arrasada com os comentários da A2. Ela bem que podia ter passado sem essa.

Pesq.: Mas eu achei bom ela ter dito o que estava pensando. Ela nos deu uma oportunidade de olhar a atividade por meio dos olhos dela e ver, assim, o trabalho a partir de outro ângulo, que é o ponto de vista de uma criança. Isso enriquece a nossa experiência, faz da gente professoras ainda melhor.

Nina: Claro, a vantagem é essa. Mas tinha que acontecer logo quando vocês estavam filmando? Hoje, eu queria que tudo tivesse dado certo, para as crianças, para vocês e para mim.

Pesq.: Acho que a A2 nos deu um alerta importante: que é preciso tomar muito cuidado ao planejar atividades, porque o conteúdo precisa ter significado para quem aprende, precisa se relacionar com a vida deles. Ela foi bem legal.

Nina: Foi, foi sim. Ela é uma menina interessante.

Pesq.: Uma última pergunta. Por que a classe é arrumada desse jeito?

Nina: Desse jeito como?

Pesq.: Com as carteiras todas enfileiradas. Isso não atrapaIha a interação e a concentração? Os próprios alunos reclamaram do barulho...

Nina: Isso não tem saída. Se não tivesse aula à noite, ou se todos os professores usassem círculos, seria mais fácil. Mas sem ter um consenso, modificar a arrumação da sala prejudicaria as salas que estão acostumadas a trabalhar desse modo, com um aluno atrás do outro.

Pesq.: Mas isso não pode ser discutido na escola?

Nina: Pode, mas mudança é sempre um problema. Elas demoram a acontecer e a gente acaba se acostumando 
com as coisas do jeito que estão. Eu mesma já estou acostumada com o barulho e com as fileiras. Não me incomoda mais.

Pesq.: E o número das carteiras, não dá para retirar algumas?

Nina: Nem pensar. A turma que vem à noite é numerosa e não dá para ficar pondo e tirando carteiras. Algumas coisas não podem ser feitas. Eu acho que a gente precisa parar de olhar para o que não tem na escola e ver o que ela tem.

Pesq.: Está certo, Nina. Vai chegar um dia que a escola vai ser a dos nossos sonhos. Mas, para isso, precisamos cuidar da escola da realidade. Você tem toda razão.

O recorte acima indica bem o movimento que se dá ao longo das autoconfrontações: a posição da professora, que vai ganhando força na e pela reflexão, modifica-se facilitada pela observação e pela dialogia com parceiros diferenciados. De fato, como bem aponta Roger (2007), parece que Nina vai recuperando, aos poucos, seu "poder de agir". A confrontação com a segunda pesquisadora promove, portanto, um deslocamento do ponto de vista da professora, que passa a se dar conta, por intermédio da apreensão de outros, de facetas novas em sua própria atividade. Preocupada, inicialmente, em se mostrar uma boa professora para as pesquisadoras e para a diretora, Nina percebeu que a pesquisadora tinha outras coisas em mente: entender o que não estava visível na atividade e, por isso, seguia uma lógica distinta, que passou, em determinado momento, a ser partilhada. Nina passou a discutir aspectos relevantes da prática docente, da sua prática docente. Uma simetria foi estabelecida e a conversa fluiu bem, todos abrindo novas possibilidades para os outros, um permitindo aos outros refletirem sobre o que foi dito, feito, vivido. Expectativas são postas e relativizadas. Ao final da sessão, Nina relatou que, já na autoconfrontação simples, tinha se dado conta de a atividade realizada era muito complexa, o que se confirmara na autoconfrontação cruzada. Nesse momento, a atividade em si passa para um segundo plano, cedendo lugar ao sujeito da atividade.

O movimento de Nina, no sentido de recuperar seu "poder de agir" poderia ter seguido inúmeros cursos. As sessões de autoconfrontação, desse modo, não estão autorizadas a dizer o que deveria ter sido feito (ou não) na situação em análise. O papel da observação e da reflexão sobre a atividade realizada é distinto: abrir novos horizontes para os docentes e para os pesquisadores. Isso foi feito. Do ponto de vista da professora, ela passou a ter preocupações novas e que se distanciavam muito de "passar uma boa impressão". Procuravam, antes, entender as razões de se ter adotado essa atividade e não outra para aprimorar a expressão oral dos alunos. Nina, ao se apropriar das questões das pesquisadoras, deu-se conta dos efeitos involuntários da atividade realizada sobre os alunos: cansaço, aborrecimento, tédio, incompreensão acerca do que se estava fazendo. Esses efeitos, de imprevistos, passaram a constar do universo dos possíveis apenas porque a autoconfrontação cruzada permitiu descolar o foco da análise da interação professora-alunos para a própria professora que, com isso, toma consciência de novas possibilidades de ação e de novas necessidades pessoais, como a de estudar mais.

A teoria a respeito do processo de alfabetização aparece também como fonte de desenvolvimento, porque os vínculos entre ela e a atividade prática foram estabelecidos na e pela interação de Nina com as pesquisadoras. Esse é um conhecimento que não é "teórico", na medida em que constitui um problema da prática e não é, ao mesmo tempo, um conhecimento "prático", visto emergir da reflexão. A quem pertencem os conhecimentos aqui adquiridos? Aos envolvidos e, também, pela divulgação desse artigo, aos profissionais da Educação, desde que por eles legitimado.

\section{Considerações finais}

A perspectiva sócio-histórica dedica-se ao estudo do "desenvolvimento dos invariantes da atividade", ou seja, preocupa-se menos com a apreensão da estrutura da atividade enquanto tal e mais com a estrutura de seu desenvolvimento (Roger, 2007, p. 100). Dessa maneira, o interesse desta pesquisa reside nos mecanismos que promovem esse desenvolvimento. Assim, destacamos como central para nossa análise o preceito vygotskiano, segundo o qual "é somente em movimento que um corpo mostra o que é" (Vygotski, 2000 , p.86). Para apreendermos as contradições existentes na atividade do professor, é necessário que o desenvolvimento seja, ao mesmo tempo, objeto e método da investigação psicológica. Isso implica provocar o desenvolvimento, ou seja, romper com a atividade fossilizada, fazendo-a reaparecer tal como era inicialmente para daí compreender seu movimento. Isso só pode ser feito, segundo Roger (2007), porque a observação e a troca de pontos de vista deixam traços na linguagem, que se tornam, por sua vez, objeto de pesquisa.

Ao seguir os movimentos da professora, fica claro como é penoso submeter-se a ser avaliado por pessoas que poderiam pôr seu prestígio por terra. Gradativamente, ao se observar agindo e ao dialogar com diferentes interlocutores sobre as ações no vídeo, estabelece-se uma zona de desenvolvimento próximo que impulsiona o desenvolvimento pessoal e enriquece a atividade docente. As mudanças da professora vão ganhando contornos mais nítidos: se na autoconfrontação simples ela se julgou inadequada, na cruzada foi possível perceber que a atividade analisada era interessante e poderia ser aprimorada. O temor de fracassar vai pouco a pouco convivendo com sentimentos mais positivos: entusiasmo, ambição, possibilidades de renovação. Essas diversas apreensões, que se manifestaram em diferentes momentos, acabam por se interpenetrar, criando conflitos de sentidos e significados, que atingem também o pensamento sobre a atividade realizada, ocasionando outro movimento, que envolve, agora, o próprio processo de alfabetização. Isso ocorre por meio da apropriação subjetiva, intrapsico- 
lógica, do que se passava no plano interpsicológico. Novos objetivos e configurações para a atividade realizada são formulados. Pode-se afirmar, conforme Roger (2007, p. 103), que esse movimento apresenta algumas características: não ser "lido" diretamente pelos professores, que podem, no entanto, os apreender quando em interação entre si; inversamente, os docentes apreendem sua atividade de outra maneira, distinta da usual, e eles permitem que se conheça a forma pela qual trabalham. O foco da observação e da análise migra, incessantemente, dos conteúdos da atividade para a atividade em si e vice-versa.

Por último, mas não menos importante, é preciso mencionar que o "gênero" constitui a principal mediação na escolha da atividade e, inclusive, em sua condução. As muitas capacitações oferecidas pela SEE-SP em Língua Portuguesa têm salientado a necessidade de se trabalhar a expressão oral das crianças, sobretudo nas séries iniciais. No entanto, o gênero não é suficiente para assegurar que a atividade selecionada pelos docentes seja bem-sucedida, de modo que é central constituir um estilo na e pela observação do que foi feito, refletido e discutido. O estilo pessoal modifica o gênero e, eventualmente, é nele incorporado, passando a ser patrimônio dos professores. A abordagem aqui seguida fortalece não uma professora em particular, mas o conjunto de docentes, podendo ser utilizado como exemplo a ser discutido em capacitações iniciais e/ou continuadas. Com isso, fortalecem-se os docentes, uma vez que é deles o papel central de armazenar, formar e de transformar os repertórios de ação de seus membros, mediante a elaboração de outros estilos, que se vão descortinando na e pela observação, na e pela reflexão acerca da atividade docente.

\section{Referências}

Aguiar, W. M. J., \& Ozella, S. (2006). Núcleos de significação como instrumento para a apreensão da constituição dos sentidos. Revista Psicologia, Ciência e Profissão 26(2), 223-244.

Clot, Y. (1999). La Fonction psychologique du travail. Paris: PUF. Coletânea de textos: Psicologia do trabalho. Ciclo CEAP. Belo Horizonte.

Clot, Y. (2001). Éditorial. Éducation permanente: clinique de l'activité et pouvoir d'agir, 146, 7-16.

Clot, Y. (2006). A Função psicológica do trabalho. Petrópolis, RJ: Vozes.

Durand, M. e cols. (2005). Relações fecundas entre pesquisa e formação docente: elementos para um programa. Cadernos de Pesquisa 35(125), 37-62.
Freire, P., \& Shor, I. (1992). Medo e ousadia : o cotidiano do professor. Rio de Janeiro: Paz e Terra.

Freitas, H. C. L. de. (2002). Formação de professores no Brasil: 10 anos de embate entre projetos de formação. Educação e Sociedade 23(80), 136-67.

Gatti, B. A. A. (2003) Formação continuada de professores: a questão psicossocial. Cadernos de Pesquisa (119), 191-204.

Gatti, B., \& Barretto, E. S. de S. (2009). Professores no Brasil: impasses e desafios. Brasília: Unesco.

Leontiev, A. N. (1978). O Desenvolvimento do psiquismo. Lisboa: Horizonte Universitário.

Libâneo, J. C. (2003) Adeus professor, adeus professora? Novas exigências profissionais e profissão docente. São Paulo: Cortez.

Nóvoa, A. (1998) Profesionalización de docentes y ciencias de la educación. Educación y Pedagogía 9/10(19/20), 251-286.

Oliveira, D. A. (2004). A reestruturação do trabalho docente: precarização e flexibilização. Educação e Sociedade 25(89), 1.127-1.144.

Rey, F. (2004). O social na psicologia e a psicologia no social: a emergência do sujeito. Petrópolis, RJ: Vozes

Roger, J. L. (2007). Refaire son métiers: essays de la clinique de l'activité. Ramonville Sant-Agne: Érès.

Santo, L. L. de C. P. (2004). Formação de professores na cultura do desempenho. Educação e Sociedade 25(89), 1.145-1.158.

Severino, A. J. (2001). Educação, sujeito e história. São Paulo: Olho d'Água.

Talavera, M. del C. F. (2004). De la formación a la práctica docente: un estudio de los procesos de transferencia de los profesores. Revista Latino Americana de Estudios Educativos 34(3), 37-68.

Vygotski, L. S. (2000). A construção do pensamento e da linguagem. Martins Fontes: São Paulo.

Vygotski, L. S. (2000). A formação social da mente. Martins Fontes: São Paulo. 
Recebido em: 20/07/2009 Reformulado em: $12 / 05 / 2010\left(1^{\text {a }}\right.$ Reformulado em: 15/06/2010 (2a)

Reformulado em: 23/09/2010 (3a)

Aprovado em: 01/10/2010

\section{Sobre as autoras}

Claudia Davis (claudiadavis@pucsp.br)

Pontifícia Universidade Católica de São Paulo, São Paulo - SP

Wanda Maria Junqueira Aguiar (iajunqueira@uol.com.br)

Pontifícia Universidade Católica de São Paulo, São Paulo - SP

\section{Correspondência}

Claudia Davis

Rua: Monte Alegre, 984

CEP: 05014 São Paulo - SP 